\title{
Skin Manifestations of Hypothyroidism-A Clinical Study
}

\author{
S.Haritha ${ }^{1}$, K. Kirthi Sampath ${ }^{2}$ \\ ${ }^{1}$ (Assoc. Professor, Department of Dermatology, Dr. Pinnamaneni Siddhartha institute of Medical Sciences \& \\ Research Foundation, Chinoutpall, Andhra Pradesh, India) \\ ${ }_{2}^{2}$ (Post Graduate, Department of Dermatology, Dr. Pinnamaneni Siddhartha institute of Medical Sciences \& \\ Research Foundation, Chinoutpall, Andhra Pradesh, India)
}

\begin{abstract}
Thyroid disorders are known to cause a wide range of skin manifestations. Hypothyroidism causes changes in the skin, hair and nails. The aim of our study was to evaluate the skin manifestations in patients with hypothyroidism. A total of 100 patients with hypothyroidism attending the General Medicine and Dermatology of Dr. Pinnamaneni Siddhartha Institute of Medical Sciences over a period of one year were included in our study, and the skin lesions have been recorded after a detailed history and clinical examination. Out of 100 patients, 63 patients had skin manifestations. Xerosis (acquired ichthyosis) and diffuse hair loss were the common skin manifestations which were seen in $38.09 \%$ and $34.8 \%$ of patients respectively. Melasma(14.28\%), chronic urticaria $(14.28 \%)$ and generalised pruritus(11.1\%) were the other common manifestations. Tinea corporis, vitiligo, alopecia areata, lichen planus and xanthelasma palpebrarum were the other skin disorders associated with hypothyroidism. We therefore conclude that a better understanding of the skin lesions helps in the early detection of the underlying hypothyroid state.
\end{abstract}

Keywords - Hypothyroidism, Skin changes, Xcrosis

\section{INTRODUCTION}

Thyroid disorders are known to involve all organ systems of the body including the skin. Thyroid hormones have been shown to be necessary for the initiation and maintenance of hair growth as well as normal secretion of sebum. ${ }^{1}$ Both hypothyroidism and hyperthyroidism are known to cause skin changes. Hypothyroidism is generally associated with thick, dry, cold and pale skin. The dryness may be so severe that it resembles an acquired ichthyosis.

The most classical cutaneous finding of hypothyroidism is generalized myxedema, where the skin typically appears doughy, swollen, and waxy to touch.

Hair of the scalp and body is classically dry, coarse, and brittle, and tends to fall out loosely resulting in diffuse or partial alopecia. The rate of nail growth is slowed, and nails become brittle with longitudinal and transverse striations. ${ }^{2}$

Many other skin disorders like vitiligo, melasma, alopecia areata, xanthelasma palpebrarum, are found to be associated with hypothyroidism. ${ }^{3}$

Dermatologists may commonly see skin disorders that reflect an underlying hypothyroid state. The aim of our study is to evaluate the cutaneous manifestations in patients with hypothyroidism

\section{MATERIALS AND METHODS}

The study sample consisted of 100 diagnosed cases of hypothyroidism who attended the General Medicine \& Dermatology OPD of Dr. Pinnamaneni Siddhartha Institute of Medical Sciences, during the period of January 2012 to December 2012. The study was approved by the Institutional Ethics Committee.

A detailed history regarding socio demographic profile and clinical history was taken after obtaining written consent from all the participants who were included in the study. A thorough cutaneous examination was done and the skin lesions were noted. Specific investigations like Thyroid Function tests were done for all the cases to establish the hypothyroid state of the subjects. Relevant haemotological investigations and skin biopsy were done where ever required.

\section{RESULTS}

Results show that $76 \%$ were females and $24 \%$ were males. Out of the total study population 63 patients had skin manifestations, which included $85.71 \%$ of females and $14.29 \%$ of males. Few patients had more than one skin manifestation. The various cutaneous changes observed have been shown in the table. Xerosis and diffuse hair loss (telogen effluvium) were the most common findings which were seen in $38.08 \%$ and $34.8 \%$ of the study population. Melasma (14.28\%), chronic urticaria(14.28\%), generalised pruritus(11.1\%), skin tags $(9.52 \%)$ and tinea corporis $(7.93 \%)$ were the other common findings. The other associated skin disorders were alopecia areata(6.34\%), vitiligo(4.76\%), lichen planus(3.17\%) and xanthelasma palpebrarum(1.58\%). 


\section{DISCUSSION}

In our study which included 100 patients with hypothyroidism, females constituted $76 \%$ and males constituted $24 \%$ which is consistent with earlier studies which have shown high female predominance. ${ }^{3,4}$.

Skin manifestations were seen in 63\% of the study population. Dr.Joan Felicita Samson reported skin manifestations in $54 \%$ of patients with thyroid disorders. ${ }^{4}$ Xerosis was the most common skin change which was encountered in $38.08 \%$ of the patients. Alka Dogra et al reported coarse and dry skin in 56\% of patients in their study. ${ }^{3}$ Hypohidrosis accompanied by cytologic changes within the eccrine apparatus and diminished sebaceous gland secretion have been considered as potential etiologic factors. ${ }^{5} 34.8 \%$ had diffuse hair loss (telogen effluvium). Alopecia of hypothyroidism is mediated via hormone effect on the initiation as well as duration of hair growth and normal telogen-anagen hair relationships were restored with thyroid hormone replacements. ${ }^{6}$ Chronic idiopathic urticaria was reported in $14.28 \%$ of patients in our study. Alka Dogra et al reported $15.6 \%$ of patients with urticaria in their study. ${ }^{3}$ Leznoff and Sussman evaluated 624 patients with chronic idiopathic urticaria and angioedema and found 90 patients to have evidence of thyroid disorder. ${ }^{7}$ Heymann has stated that the mechanism by which thyroid autoimmunity is associated with urticaria is poorly understood, and there is clustering of thyroid microsomal antibodies in patients with positive analogous serum test, although it is unlikely that thyroid hormone itself has any in vivo effect on cutaneous vascular response to histamine and on the mas cell releasability. ${ }^{8} 14.28 \%$ of patients had melasma in our study. The association between hypothyroidism and melasma has been documented by Lufti and Neipomniszce. ${ }^{9,10}$

Tinea corporis was observed in our study which could be because of the humid climate in our area. Moreno et al reported patients with tinea cruris and tinea corporis in their study. ${ }^{11}$ Vitiligo was present in 3 patients in our study, a finding which is similar to that of Joan Felicita et al. ${ }^{4}$ Alopecia areata was seen in 4 patients in our study and many studies have shown the association of alopecia areata and thyroid disorders. ${ }^{12,13}$

\section{TABLES}

Table showing the various skin changes in Hypothyroid patients.

\begin{tabular}{|c|c|c|}
\hline Skin lesions & Number of patients & $\%$ \\
\hline Xerois (acquired ichthyosis) & 24 & 38.09 \\
\hline $\begin{array}{c}\text { Diffuse hair loss (Telogen } \\
\text { effluvium) }\end{array}$ & 22 & $34.8 \%$ \\
\hline Melasma & 9 & 14.28 \\
\hline Chronic urticaria & 9 & 14.28 \\
\hline Generalized pruritus & 7 & 11.11 \\
\hline Tinea corporis & 5 & 7.93 \\
\hline Alopecia areata & 4 & 6.34 \\
\hline Vitiligo & 3 & 4.76 \\
\hline Lichen planus & 2 & 3.17 \\
\hline Xanthelasma palpebrarum & 1 & 1.58 \\
\hline
\end{tabular}

63 patients had skin manifestations and few patients had more than one skin lesion.

\section{CONCLUSION}

From our study we conclude that certain skin disorders are very common and strongly associated with hypothyroidism. Dermatologists commonly see skin lesions that reflect an underlying hypothyroid state. A proper understanding of the skin manifestations helps in the prompt and early detection of hypothyroidism.

\section{REFERENCES}

[1]. Goolamali SK. Thyroid disease and sebaceous gland function. Br. Med J. 1979; $1: 432-440$.

[2]. Khurram Irfan M, Choudary Kiran, Muhammad Khan, Islam Najmul. Clinical presentation of hypothyroidism in central part of Iran.Pak J Med Sci.2008 Jan-Mar;24(1):44-7.

[3]. Dogra A, Dua A, Singh P. Thyroid and skin. Indian J Dermatol 2006; 51: 96-99.

[4]. Joan Felicita Samson, P.S. Mathew, G.K. Libu, B. Jayakumar. Astudy of cutaneous manifestations of hypothyroidism and hyperthyroidism. Kerala Medical Journal 2011; 52-54

[5]. Means MA, Dobson RL. Cytologic changes in the sweat gland in hypothyroidism. JAMA 1963; 186: 113-5

[6]. Feingold KR, Elias PM. Endocrine Skin Interactions. J Am Acad Dermatol 1987; 17: 920-940.

[7]. Leznoff A, Sussman GL. Syndrome of Idiopathic chronic Urticaria and angioedema with thyroid autoimmunity: A study of 90 patients. J Allergy Clin Immunol 1989;84: 66-71.

[8]. Heymann WR. Chronic urticaria and angioedema associated with thyroid autoimmunity; Review and therapeutic implications. J Am Acad Dermatol1999; 40: 229-232.

[9]. Lufti RJ, Fridmanis M, Misiunas AL, Pafume O, et al. Association of melasma with thyroid autoimmunity and other thyroid abnormalities and their relationship to the origin of melasma. J Clin Endocrinol Metab 1985; 61: 28-31.

[10]. Niepomniszcse H, Amad RH. Skin disorders and thyroid. Endocrinol Invest 2001; 24: 628-38. 
[11]. Moreno AJ, Hartshorne MF, Yedinak MA, Crooks LA, Fox BJ. Tinea corporis overlying thyroid gland after radio iodine treatment of Grave's disease. Cutis 1986; 37: 271-3

[12]. Milgraum SS, Mitchel AJ, Bacon GE, Rasmussen JE. Alopecia areata, endocrine function and in patients aged 16 years or younger. J Am Acad Dermatol 1987; 97: 57-61.

[13]. Tosti A, Bardazzi F, Guerra L. Alopecia areata and throid function. J Am Acad Dermatol 1988; 19:1118-9. 